\title{
Intelligent analysis of active management of animal husbandry
}

\author{
Stanislav Dimitrov ${ }^{1}$, Todor Stoilov ${ }^{1 *}$, and Krasimira Stoilova ${ }^{1}$ \\ ${ }^{1}$ Institute of Information and Communication Technologies - Bulgarian Academy of Sciences, \\ 1113, Acad. G. Bonchev str. Bl.2, Sofia, Bulgaria
}

\begin{abstract}
A quantitative analysis of the financial state of an animal husbandry is performed. The paper illustrates the usage of different economical parameters in order to present operational state of the husbandry and to search regularities for future actions. The added value of this research is the application of intelligent instruments in the management of the economic behavior of animal husbandry which give recommendations for their more effective functionality.
\end{abstract}

\section{Introduction}

The growth of modern technological solutions like information technologies, automation, artificial intelligence allows their power to be applied in traditional animal husbandry. These technologies allow to be quantified, numerical assess and forecast the economic behavior of business entities. Such an entity can be regarded the operation of an animal husbandry, which have to manage its inventory with foods and materials for the animal feeding. A simultaneous activity is the transfer of the production to retailers and customers of animal productions and related goods. The efficient management of the husbandry can give rise in the productivity and sustainable development of the animal farms by increasing the economic growth and decreasing the recourses in husbandry operations and human efforts.

The usage of information technologies applications can lead to implementation of automation of different stages of the economic management of the husbandry. Respectively, it can implement intelligent solutions in data acquisition, analysis and support of decision making in the business management. It is expected that such intelligent solutions can result in increase of the animal production, to achieve profitable and efficient operation of the husbandry activities. These expectations make natural the tendencies of intensification of development and implementation of intelligent applications of animal productivity and sustainability [1]. The usage of intelligent solutions on husbandry management prevents managers from ineffective decision making. Thus, the risk in husbandry management is considerably decreased.

The application of intelligent technological solutions in animal husbandry can assess in real time the current state of its operational life. This is performed by qualitative analysis of

* Corresponding author : todor.stoilov@iiict.bas.bg 
financial and material flows which participate like input and output recourses and production outcomes of the animal husbandry. Based on a qualitative evaluation it is identified the tendencies of the future behavior of the husbandry.

The researches and attempts for implementation of intelligent solutions in animal husbandry are increasing activities for finding practical and scientific solutions. The inventory management is an important part of the efficient operation of the animal husbandry. Research methods and models for inventory management are intensively developed for a long time in the domain of operational researches [2]. Practical applications for animal husbandry with intelligent solutions are currently developed in [3]. Intelligent integration between sells and inventory are discussed and formalized in [4]. Without claiming of extended overview about variety of intelligent solutions in animal husbandry we can point of activities for image classification of forage plants [5]; animal welfare management [6]; application of information technologies for the design of integrated animal husbandry livestock management system [7]. The general problems of the application of intelligent solutions in animal husbandry and aquaculture industry are discussed in $[8,9]$. The influence of the digital world to the animal welfare, surveillance of their health and improvement of the animal welfare is analyzed in [10]. Innovative techniques in animal husbandry are discussed in [9]. This short overview gives evidences that the research and practitioners pay considerable attention towards the application of innovative and intelligent solutions for non-pure technical domains like animal husbandry. This paper makes an attempt to apply quantification approaches for the management of animal husbandry. The quantification analysis is able to estimate tendencies in incomes and to assess the most effective activities in the husbandry. The quantification analysis allows being identified peculiarities of the management which are not directly evident. This research gives an intelligent solution for the animal husbandry analysis, which is not computational difficult, but it cannot be estimated directly by simple analysis of the available operational data of the husbandry.

\section{Analysis of the husbandry management from a set of initial data}

The task of this section is to identify the minimal set of data, which can be used for the analysis of the husbandry management. To illustrate numerically the proposed approach here are given data from [11]. The minimal sets of used data are the integral numbers for a last year (LY) of the husbandry and the time records per months for the current year (CY). The values per category are summarized as "cash receipt" and "cash disbursement". Each category of cash is identified by their appropriate components:

- The "receipt" category contains components as: crop sales, livestock sales, government payments for support, others.

- The "disbursement" category contains many components like: seed, fertilizers, chemicals, crop insurance, fuel, labour, machines, building expenses, property taxes, insurances, cash rent, miscellaneous, family living.

- As additional category is included the "Debt obligations", which concern equipment, farmland mortgage and building loan.

In Table 1 these categories of "receipt" and "disbursements" are presented with their values. The column "Last year" (LY) gives the integral value of each component for the husbandry management. The next columns give values of each component per month. The last two columns summarize the integral value for the current year (CY) and the average monthly value per category. 
Table 1: Initial data for the husbandry management [11]

\begin{tabular}{|c|c|c|c|c|c|c|c|c|c|c|c|c|c|c|c|c|}
\hline Cash flow budget & Total Last year & Average Month LY & Ian & Feb & Mar & Apr & May & Jun & Jul & Aug & Sep & loct & Nov & Dec & Total Current Year & Average Month $\mathrm{CY}$ \\
\hline \multicolumn{17}{|l|}{ Cash Receipt } \\
\hline \begin{tabular}{|l} 
Crop Sales \\
\end{tabular} & 950000 & 79166,67 & 0 & 0 & 0 & 0 & 300000 & 300000 & 0 & 0 & o & 220000 & 180000 & 180000 & 1180000 & 98333,33 \\
\hline Livestock sales & 450000 & 37500,00 & 0 & 0 & 25000 & 0 & 0 & 181250 & 0 & 0 & 290000 & 0 & 0 & 53750 & 550000 & 45833,33 \\
\hline Government payments & 9800 & 816,67 & 0 & 0 & 0 & 0 & 0 & 0 & 9800 & 0 & 0 & 0 & 0 & 0 & 9800 & 816,67 \\
\hline Other & 30000 & 2500,00 & 0 & 0 & 0 & 0 & 0 & 16000 & 16000 & 0 & 0 & 0 & 0 & 0 & 32000 & 2666,67 \\
\hline Total Cash Receipts & 1439800 & 119983,33 & 0 & 0 & 25000 & 0 & 300000 & 497250 & 25800 & 0 & 290000 & 220000 & 180000 & 233750 & 1771800 & 147650,00 \\
\hline \multicolumn{17}{|l|}{ Cash Disbursement } \\
\hline Seed & 85000 & 7083,33 & 0 & 0 & 31167 & 0 & 0 & 0 & 0 & 0 & 0 & 0 & 0 & 62333 & 93500 & 7791,67 \\
\hline Fertilizer & 120500 & 10041,67 & 0 & 0 & 0 & 32535 & 0 & 0 & 0 & 0 & 0 & 0 & 97605 & 0 & 130140 & 10845,00 \\
\hline Chemicals & 52000 & 4333,33 & 0 & 0 & 0 & 0 & 17680 & 17680 & 17680 & 0 & 0 & 0 & 0 & 0 & 53040 & 4420,00 \\
\hline Crop Insurance & 35400 & 2950,00 & 37170 & 0 & 0 & 0 & 0 & 0 & 0 & 0 & 0 & 0 & 0 & 0 & 37170 & 3097,50 \\
\hline Fuel \& utililies & 42750 & 3562,50 & 3776 & 3776 & 3776 & 3776 & 3776 & 3776 & 3776 & 3776 & 3776 & 3776 & 3776 & 3776 & 45312 & 3776,00 \\
\hline Labor & 36000 & 3000,00 & 2000 & 2000 & 4000 & 4000 & 2000 & 2000 & 2000 & 2000 & 5000 & 5000 & 5000 & 2000 & 37000 & 3083,33 \\
\hline Machine \& Equipment & 54775 & 4564,58 & 4702 & 4702 & 4702 & 4702 & 4702 & 4702 & 4702 & 4702 & 4702 & 4702 & 4702 & 4702 & 56424 & 4702,00 \\
\hline Building Expenses & 9900 & 825,00 & 0 & 0 & 0 & 0 & 0 & 3234 & 3234 & 3234 & 0 & 0 & 0 & 0 & 9702 & 808,50 \\
\hline Property Taxes & 8200 & 683,33 & 0 & 0 & 0 & 4100 & 0 & 0 & 0 & 0 & 0 & 4100 & 0 & 0 & 8200 & 683,33 \\
\hline \begin{tabular}{|l|} 
Insurance \\
\end{tabular} & 9100 & 758,33 & 0 & 0 & 0 & 0 & 0 & 4732 & 0 & 0 & 0 & 0 & 0 & 4732 & 9464 & 788,67 \\
\hline \begin{tabular}{|l} 
Cash Rent \\
\end{tabular} & 316000 & 26333,33 & 0 & 0 & 158000 & 0 & 0 & 0 & 0 & 0 & 0 & 0 & 0 & 158000 & 316000 & 26333,33 \\
\hline Miscellaneous & 11000 & 916,67 & 833 & 833 & 833 & 833 & 833 & 833 & 833 & 833 & 833 & 833 & 833 & 833 & 9996 & 833,00 \\
\hline \begin{tabular}{|l} 
Family Living \\
\end{tabular} & 40000 & 3333,33 & 3500 & 3500 & 3500 & 3500 & 3500 & 3500 & 3500 & 3500 & 3500 & 3500 & 3500 & 3500 & 42000 & 3500,00 \\
\hline Total Cash Disbursements & 820625 & 68385,42 & 51981 & 14811 & 205978 & 53446 & 32491 & 40457 & 35725 & 18045 & 17811 & 21911 & 115416 & \begin{tabular}{|l|l|}
5 & 239876 \\
\end{tabular} & 847948 & 70662,33 \\
\hline \multicolumn{17}{|l|}{ Debt Obligations (P\&I) } \\
\hline Equipment Note & 21061 & 1755,08 & 0 & of & 0 & 0 & 10531 & 0 & 0 & 0 & 0 & 0 & t) & 10531 & 21062 & 1755,17 \\
\hline Farmland Mortgage & 70683 & 5890,25 & 0 & 70683 & 0 & 0 & 0 & 0 & 0 & 0 & of & 0 & 0 & 0 & 70683 & 5890,25 \\
\hline Building Loan & 11475 & 956,25 & 0 & & 0 & 0 & 0 & 0 & 0 & 0 & 10880 & 0 & 0 & 0 & 10880 & 906,67 \\
\hline Total debt Oblications & 103219 & 8601,58 & 0 & 70683 & 0 & 0 & 10531 & 0 & 0 & 0 & 10880 & 0 & 0 & 10531 & 102625 & 8552,08 \\
\hline
\end{tabular}


The easier and simple analysis of this set of data can be their graphical presentation under different criteria. Such form of presentation gives another view of the set of numerical data. It is more convenient for the manager to assess peculiarities and tendencies. But the explicit presentation in graphical form of this set of numerical data does not identify inexplicit relations and parameters for the husbandry management. Such inexplicit parameter is the risk management of appropriate category of the farm operation. Nevertheless, of the simple form of the graphical analysis, here it will be illustrated several solutions for quantified assessment of the economical behavior of the husbandry.

On Fig. 1 it is given the income values for the category of "receipt". Each cash receipt is decomposed per month of the current year. The income from agriculture production is given in blue color. The income from animal production is presented with orange. Such form of analysis identifies easily that the animal production gives income mainly in two months: September and June. In general, the animal incomes are irregularly distributed in the year. This means that the animal husbandry management has to keep considerable inventory by means to keep regular animal welfare and rules of life. The average monthly income for LY is presented in green, and the corresponding monthly results for the CY are in blue. Evidently, for the CY the management results are better, because the monthly average cashes are higher in comparison with the LY case.

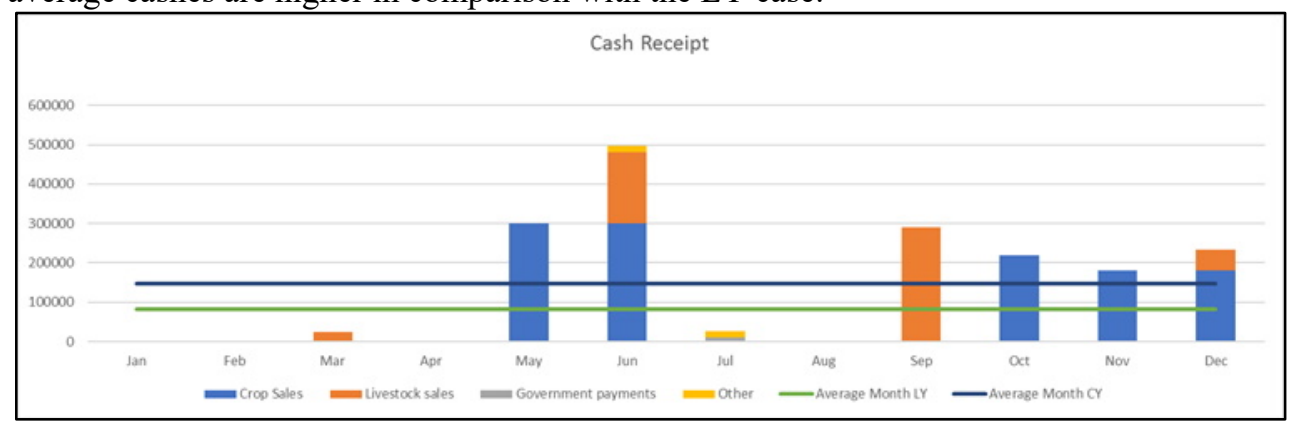

Fig. 1. Time series of incomes per month for the current year

The individual income component can be presented in a circle diagram, illustrated in Fig.2. Such a diagram explicitly shows that the livestock sales are pretty twice lower in comparison with the crop sales. Thus, for the case of specialization in animal husbandry, the management of the farm has to concentrate investments in livestock tasks.

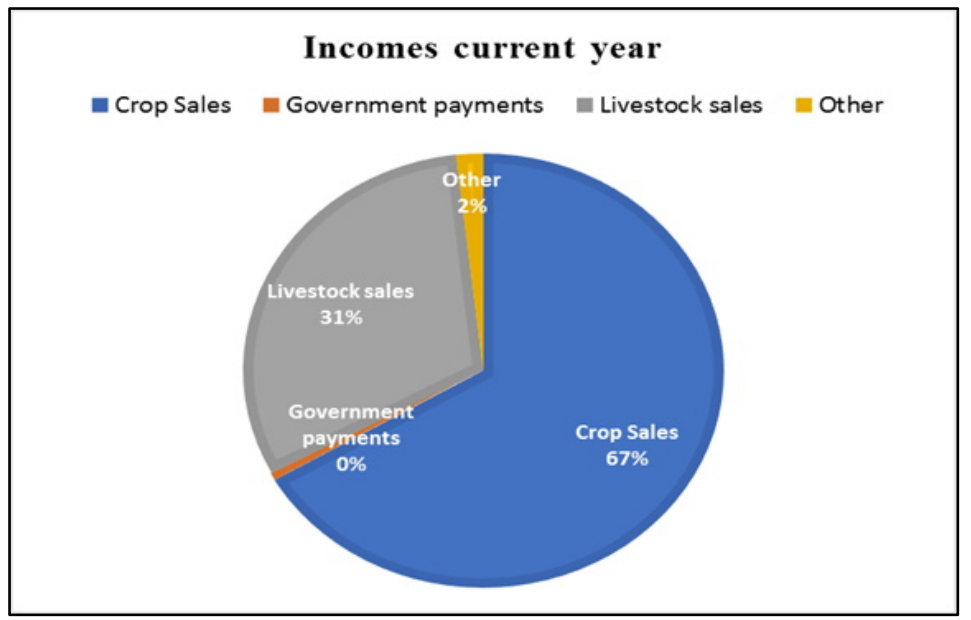


Fig. 2. Integral presentation of incomes per category for the current year

The same form of analysis can be applied for the disbursement of the farm management. Their presentation per month for the current year is given in Fig. 3. It is evident that the most amount of disbursement is allocated for cash rent, but it takes twice months per year. The months of the lowest expenses are February, August and September. Respectively, the months of March and December insist the biggest payments by the farm management.

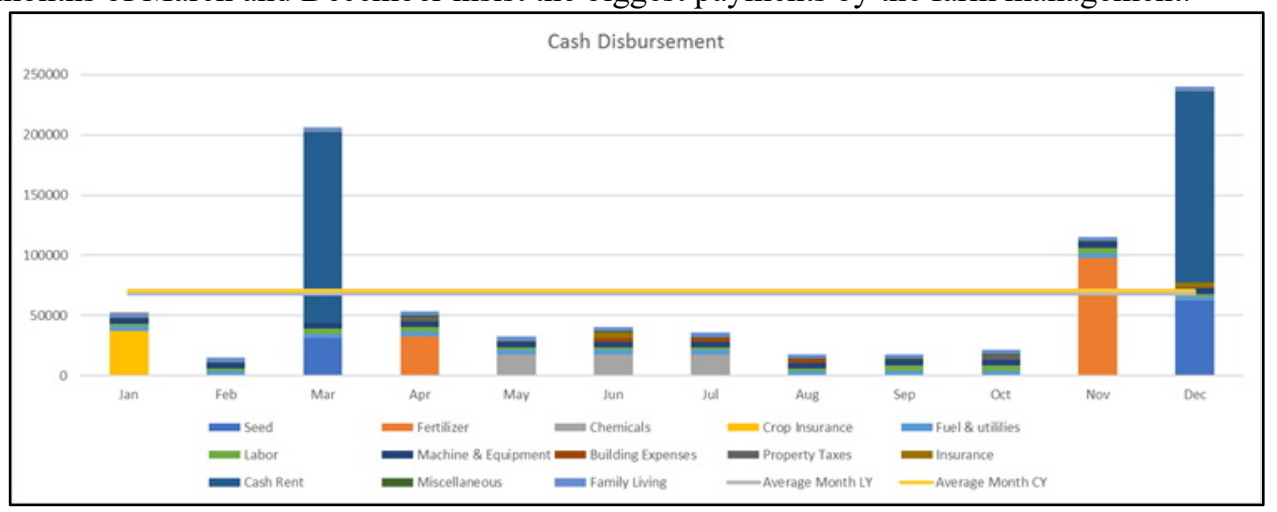

Fig. 3. Time series of disbursements per month for the current year

The comparisons between the average monthly disbursement for the current and last years are pretty the same given by the horizontal lines in the diagram. From Table 1 it is easy to estimate that the average monthly receives (147650) are prevailing the average monthly disbursement 70662.33) together with the average monthly debt obligations (8552.08). This is proving that the current management of the husbandry is effective, and it gets increase in the incomes comparing LY and CY.

The usage of the circle diagram illustrates the main categories of disbursement, which take place for the farm management. It is seen that the prevailing expenditures $(37 \%)$ are going for rents, followed by fertilizers (15\%) and seeds (11\%). For labour and family living the costs for the current year are $5 \%$ per category. The farm management has to estimate if these amounts correspond with the efforts, which are allocated for the farm operations.

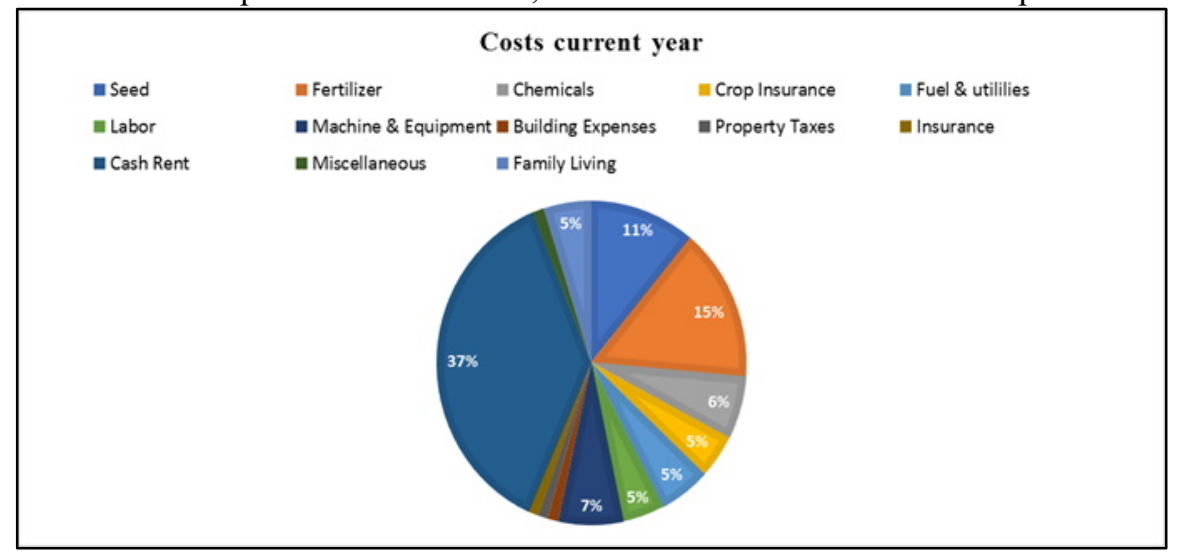

Fig. 4. Integral presentation of disbursements per category for the current year

The final analysis concerns the debt obligations and their payments in the year. On Fig. 5 is given the time division of the obligation. Evidently, the farmland mortgage is the 
biggest amount obligations, which is due on February. Compared with Fig.3 of the disbursements, the month of February is the lowest month in the year for cash payments. This is a good choice of the husbandry management to pay their obligations, when the cash expenses are lower.

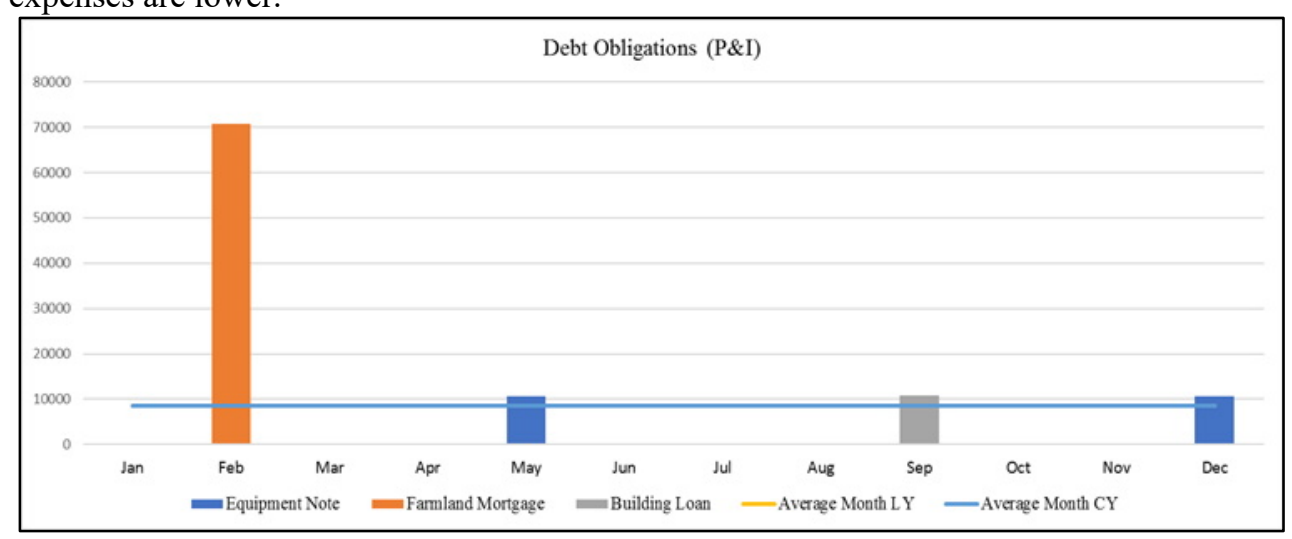

Fig. 5. Time series of obligations per month for the current year

The payments for equipment in May and building loan in September correspond with the higher incomes from Fig.1. Thus, the debt obligations in appropriate way in time are covered with the incomes of the farm. The relative amounts of the obligations are given in circle graphics in Fig.6.

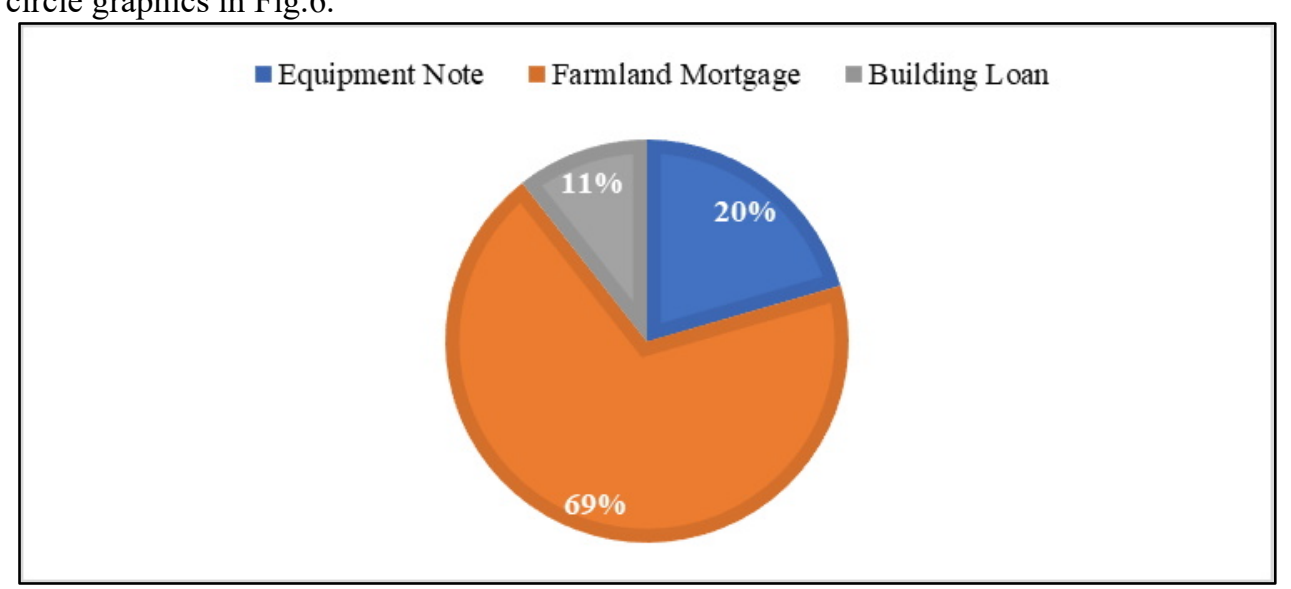

Fig. 6. Integral presentation of debt per category for the current year

The biggest component in debts is the farmland mortgage (69\%) followed by equipment $(20 \%)$.

Using the graphics from Figs. 1, 3 and 5 it is easy to estimate the critical months, when the expenditures are higher than the incomes: January, February, April, July, August, and December. May is the most beneficial month for the husbandry and the received resources this month has to be allocated appropriately for covering the lacks in the critical months described above.

These forms of analysis give an explicit view of the husbandry management. The farm management needs additional intelligent procedure for estimating the intensity between the 
different components of the incomes and expenses of the farm. Such an analysis is described in the next section of this research.

\section{Identification of management behavior by quantitative analysis}

In this section we are trying to find some dependencies leading to summarizing conclusions for decision making of the husbandry management. As there are inexplicit values of the categories characterizing the husbandry, it is a prospective practice to identify some features and tendencies, typical for its functionality. In that manner the manager can obtain information which is useful for the more effective husbandry management.

\section{Evaluation of mean values of incomes and disbursements}

This quantitative analysis has been applied for the definition of two columns in Table1 for the LY and CY. These evaluations are performed according to the relation.

$$
E_{i}=\sum_{k=1}^{T} \frac{R_{i}^{(k)}}{T}
$$

where

- $\quad E_{i}$ is the expected average income/disbursement per category $i$,

- $\quad R_{i}$ is the current value of the category estimated for the month;

- $\quad T$ is the time duration for the average calculations; $k$ is the discrete time of data.

Currently, Table 1 gives monthly data where $k=1, \ldots, 12$ and $T=12$.

For this calculation it has been assumed that all data $R_{i}$ have equal probabilistic level of existence.

The comparison between the average values between equal categories for LY and CY can identify tendencies of changes as inexplicit values of the quality of the husbandry management.

Numerical estimation of tendency of change per category

These evaluations result from the common usage of mean values per category for CY and LY. The applied relation is

$$
\Delta E_{i}=\frac{E_{i}^{(C Y)}-E_{i}^{(L Y)}}{E_{i}^{(L Y)}}
$$

where $E_{i}^{(C Y)}$ and $E_{i}^{(L Y)}$ are the mean average values per category $i$, for the CY and LY.

The tendency of changes $\Delta E_{i}$ is estimated in increase if the value $\Delta E>0$ and decrease for $\Delta E<0$. Table 2 illustrates the estimated tendencies in changes of the categories of the husbandry. It is seen that the cash receipts are increased with $23 \%$ in comparison with the last year. Another well-defined tendency is the decrease of debt obligations with $1 \%$. The disbursements are increased slowly in average with $3 \%$ which is a good result in comparison with the increased of receipts. A graphical way of presentation of the data in Table 2 is given in Fig. 7.

Table2. Tendencies of changes of the husbandry categories 


\begin{tabular}{|c|c|}
\hline Cash flow budget & Different $\Delta E_{i}$ \\
\hline Crop Sales & 0,24 \\
\hline Livestock sales & 0,22 \\
\hline Government payments & 0,00 \\
\hline Other & 0,07 \\
\hline Seed & 0,10 \\
\hline Fertilizer & 0,08 \\
\hline Chemicals & 0,02 \\
\hline Crop Insurance & 0,05 \\
\hline Fuel \& utililies & 0,06 \\
\hline Labor & 0,03 \\
\hline Machine \& Equipment & 0,03 \\
\hline Building Expenses & $-0,02$ \\
\hline Property Taxes & 0,00 \\
\hline Insurance & 0,04 \\
\hline Cash Rent & 0,00 \\
\hline Miscellaneous & $-0,09$ \\
\hline Family Living & 0,05 \\
\hline Equipment Note & 0,00 \\
\hline Farmland Mortgage & 0,00 \\
\hline Building Loan & $-0,05$ \\
\hline Total Cash Receipts & 0,23 \\
\hline Total Cash Disbursements & 0,03 \\
\hline Total Debt Oblications & $-0,01$ \\
\hline
\end{tabular}




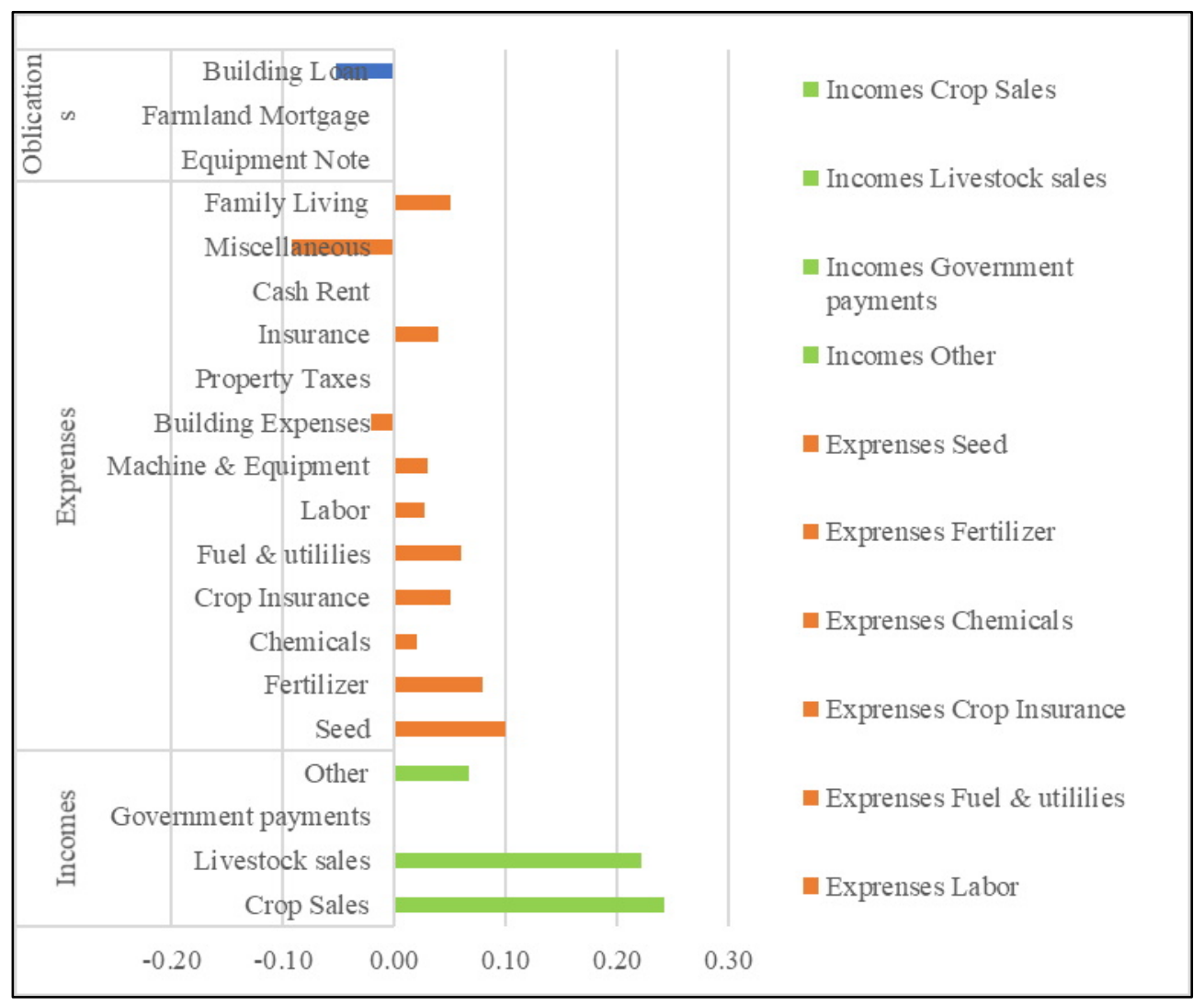

Fig. 7. Rate of changes of the cash flows

It is identified considerable increase of the incomes from livestock (22\%) and crop sales (24\%). The decrease of miscellaneous expenditures $(7 \%)$ and building expenses $(5 \%)$ is also a good result. But the increases in fertilizers costs $(8 \%)$, seed $(10 \%)$ and fuel $(3 \%)$ are events, which the management of the husbandry cannot change but it is obligatory to be considered in the management and inventory decisions. The labor costs also achieve an increase of $3 \%$.

\section{Conclusions}

The paper presents a quantitative method for analysis and estimation of financial behavior of animal husbandry. Except quantitative evaluations, graphical illustrations are applied which give easier picture about the husbandry management. The paper presents an intelligent solution for analysis and comparison of the husbandry parameters. This allows being planned appropriate payments, debts, and optimal inventory policy. Evaluation of mean values of incomes and disbursements is done. This allows to be done comparison between the average values of equal categories of the last and current year and can be identified tendencies of changes as inexplicit values of the quality of the husbandry management. The quantitative analysis can be extended by means to assess the risk and return of the husbandry management which are the next steps of the research. 
The research leading to these results has received funding from the Ministry of education and science under the National science program INTELLIGENT ANIMAL HUSBANDRY, grant agreement N Д01-62/18.03.2021

\section{References}

1. Z. Xu., Y. He, D. Ma, J. Wang, L. Zhang, Design and Implementation of Intelligent Feeding System Based-on the oneM2M, In Proceeding of IEEE 2nd International Conference Big Data Artificial Intelligence and Internet of Things Engineering (ICBAIE) (2021)

2. D. Bartmann, M. J. Beckmann, Inventory control: models and methods, (SpringerVerlag Berlin Heidelberg New York, 1992), ISBN 3-540-55820-9

3. O. A. Madamidola, O. A. Daramola, K. G. Akintola, IJTSRD, 1, 4 (2017)

4. S. Anigbogu, O. F. Oladipo, K. Usman, Indian J. Comput. Sci. Eng., 2, 5 (2011).

5. T. Pinthong, W. Yimyam, N. Chumuang, M. Ketcham, P. Pramkeaw, N. Utakrit, Image Classification of Forage Plants in Fabaceae Family Using Scale Invariant Feature Transform Method, in Proceeding of 15th International Joint Symposium on Artificial Intelligence and Natural Language Processing (2020)

6. H. Buller, H. Blokhuis, K. Lokhorst, M. Silberberg, I. Veissier, Animals, 10, 1779 (2020)

7. K. Saravanan, S. Saranya, J. Adv. in chemistry, 136 (2017)

8. C. Yongqiang, L. Shaofang, L. Hongmei, T. Pin, C. Yilin, Application of Intelligent Technology in Animal Husbandry and Aquaculture Industry, in Proceeding of 14th International Conference on Computer Science \& Education (2019)

9. S. Göncü, C. Güngör, The Innovative Techniques in Animal Husbandry, in Book Animal Husbandry and Nutrition, IntechOpen, (2018)

10. H. Buller, H. Blokhuis, K. Lokhorst, M. Silberberg, I. Veissier, J. Animals, 10, 1779 (2020)

11. A. Miller, Farm Record Keeping and Financial Analysis, (2013), https://docplayer.net/3437402-Farm-record-keeping-and-financial-analysis.html 